\title{
CONGENTRATED LOADS ON A FLOATING ICE SHEET
}

\author{
By D. E. Nevel \\ (U.S. Army Cold Regions Research and Engineering Laboratory, Hanover, \\ New Hampshire 03755, U.S.A.)
}

Abstract. The safe bearing capacity of a floating ice sheet is usually determined by limiting the maximum tensile stress which occurs under the load at the bottom of the ice sheet. If the size of the load distribution is large compared to the ice thickness, the thin plate theory predicts these stresses correctly. However, if the size of the load distribution becomes small compared to the ice thickness, the plate theory overestimates the stresses. In this case the ice sheet should be treated as a three-dimensional elastic layer.

Previous investigators have solved the elastic-layer problem for loads distributed over a circular area, and have limited the results to the stress at the bottom of the ice sheet directly under the center of the load. In the present paper the stresses are evaluated at any radial position, and it is shown how these stresses approach those for the plate theory as the radial position becomes large. The solutions for the stresses are presented in integral form, as well as graphs from the numerical integration. These new results are significant for the superposition of stresses when two concentrated loads act near each other.

Similarly for loads distributed over a rectangular area, the plate theory will overestimate the stresses if the dimensions of the load becomes small compared to the ice thickness. For this case integral solutions are presented for the stresses, and are evaluated directly under the center of the load.

RÉsumé. Charges concentrées sur un radeau de glace flottante. La capacité maximum de charge en sécurité d'un radeau de glace flottante est d'ordinaire déterminée en limitant l'effort maximum de traction qui se produit sous la charge à la face inférieure du radeau de glace. Si l'étendue de la zone chargée est grande par rapport à l'épaisseur de la neige, la théorie des plaques minces prévoit correctement ces efforts. Cependant si l'étendue de la zone chargée devient petite par rapport à l'épaisseur de la glace la théorie des plaques minces surestime les contraintes. Dans ce cas le radeau de glace devrait être traité comme une couche élastique à trois dimensions.

Les précédents chercheurs ont résolu le problème de la couche élastique pour des charges distribuées sur une surface circulaire et ont limité leurs résultats à l'effort du fond du radeau de glace directement en dessous du centre de la charge. Dans la présente étude les contraintes sont estimées à n'importe quelle position sur le rayon, et on montre comment ces efforts se rapprochent de ceux prévus par la théorie des plaques minces lorsque le rayon devient grand. On présente les solutions sous le forme d'intégrale pour les efforts ainsi que des graphiques pour une intégration numérique. Ces nouveaux résultats sont significatifs pour la superposition des efforts lorsque deux charges concentrées agissent à côté l'une de l'autre.

De la même manière, pour des charges distribuées sur une surface rectangulaire la théorie des plaques minces va surestimer les contraintes si les dimensions de la charge deviennent petits à côté de l'épaisseur de la glace. Pour ce cas les solutions en intégrales sont présentées pour les efforts et sont estimés directement au dessous du centre de la charge.

Zusammenfassung. Konzentrierte Lasten auf einer schwimmenden Eisplatte. Die sichere Tragfähigkeit einer schwimmenden Eisplatte wird gewöhnlich durch Begrenzung der maximalen Zugkraft, die unter der Last am Grunde der Eisplatte auftritt, festgelegt. Sind die Dimensionen der belasteten Fläche gross im Vergleich zur Eisdicke, so liefert die Theorie dünner Platten korrekte Werte für diese Spannungen. Andernfalls aber führt die Plattentheorie zu übertrieben grossen Spannungen. Die Eisplatte sollte in solchen Fällen als dreidimensionale elastische Schicht behandelt werden.

Frühere Untersuchungen lösten das Problem der elastischen Schicht für kreisförmig verteilte Lasten, wobei die Ergebnisse auf die Spannung an jener Stelle der Eistafel beschränkt blieben, die unmittelbar unter dem Zentrum der Last liegt. Die vorliegende Arbeit ermittelt die Spannungen für beliebige radiale Positionen; dabei wird gezeigt, dass diese Spannungen sich denen der Plattentheorie nähern, wenn der Radialabstand gross wird. Die Lösungen für die Spannungen werden in der Form von Integralen dargestellt, zusammen mit Graphiken für die numerische Integration. Diese neuen Ergebnisse sind wesentlich für die Überlagerung von Spannungen, wenn zwei konzentrierte Lasten dicht nebeneinander wirken.

Ähnlich, ergibt sich aus der Plattentheorie eine Überschätzung der Spannungen für Lasten, die über ein Rechteck verteilt sind, wenn die Dimensionen der Last im Vergleich zur Eisdicke klein werden. Integrallösungen für die Spannungen werden auch für diesen Fall angegeben und für das Zentrum unter der Last direkt ausgewertet.

\section{INTRODUCTION}

For predicting the safe bearing capacity of a floating ice sheet, the ice sheet is usually represented by the mathematical theory of a thin plate floating on the surface of the water. This theory predicts the stresses correctly when the load is distributed over a sufficiently large area, but when the load distribution becomes small, the thin-plate theory over-estimates the stresses in the vicinity of the load. 
The first person to recognize this problem of incorrect stresses in the vicinity of a load distributed over a small area wảs Hertz (1884). He recommended that the smallest diameter of load distribution used for stress calculations should be equal to the ice thickness.

When the load is distributed over a circular area, Westergaard ( 1926 ) presented a formula for the maximum stress which occurs at the bottom of the plate directly under the center of the load. His formula was based on the solution of a three-dimensional elastic layer which was developed by Nadai (I920, see also Nadai 1925, p. 308). Nadai considered a finite, axially-symmetrical, elastic layer whose bottom surface was free of stresses and whose top surface had a normal load, uniformly distributed over a circular area. The circumferential boundary corresponded closely to that of a simple support in thin-plate theory. Westergaard evaluated this solution for the maximum stress when the radius of the load was five times the thickness of the layer. When the radius of the load was greater than 1.724 times the layer thickness, he found that the thin-plate theory gave the same stress as the three-dimensional theory. When the radius of the load was less than 1.724 times the layer thickness, he found a difference between the two theories. He then stated that the thin-plate theory could still be used provided a fictitious load radius is used. The fictitious radius $a$ was given by

$$
a=\left(\mathrm{r} .6 b^{2}+h^{2}\right)^{0.5}-0.675 h,
$$

where $b$ is the true load radius and $h$ is the ice thickness. Approximately the same results were obtained with layers whose radius-to-thickness ratios were other than five. Westergaard then stated, "The results may be applied generally to slabs of proportions such as are found in concrete pavements, with any kind of support which is not concentrated within a small area close to the load".

Woinowsky-Krieger (1933) developed the three-dimensional elastic-layer solutions in rectangular and radial coordinates for loads distributed over rectangular and circular areas respectively. He presented numerical results for the maximum tensile stresses in a simplysupported and a clamped-supported axially symmetrical elastic layer without an elastic foundation. Woinowsky-Krieger also developed equations for the deflection of plates on an elastic foundation, but he did not discuss the stresses.

Nevel (1970) considered the stresses at the bottom of the ice sheet directly under the center of a load uniformly distributed over a circular area. He used elastic-layer theory and this theory gave the same numerical results as Westergaard's "fictitious" radius method. However, the stresses when the radial coordinate $r$ was not zero were not evaluated.

It is the purpose of this paper to develop and evaluate these stresses when the radial coordinate is non-zero as well as zero. These results are important for the superposition of stresses when two concentrated loads act near each other. In addition, the equations for a rectangular load will be developed and evaluated.

\section{Cirgular loads}

Consider an ice sheet of uniform thickness floating on the surface of the water. Assume that the horizontal extent of the ice sheet is sufficiently large that we may assume the ice sheet extends to infinity in any horizontal direction. Let a load which is uniformly distributed over a circular area be applied vertically to the top surface. The increase in vertical pressure on the bottom surface due to the applied load will be equal to the unit weight of water times the vertical deflection of the bottom surface. The shearing stresses on both the top and bottom surfaces are zero.

Nevel (1970) has solved this problem when the ice sheet is considered as a threedimensional elastic layer. His method of solution for this axially symmetrical problem consisted of using a Hankel transform with respect to the radial coordinate. This method corresponds to using a Fourier transform with respect to $x$ and $y$ coordinates when axial 
symmetry occurs. From his results the stresses in the ice at the bottom surface of the ice are

$$
\frac{\left(\sigma_{\theta}+\sigma_{r}\right) h^{2}}{2 P(\mathrm{I}+\nu)}=\frac{\mathrm{I}}{2 \pi} \int_{0}^{\infty} F_{+\nu} \mathcal{F}_{0}(t R) \frac{\mathcal{F}_{\mathrm{I}}(t B)}{t B / 2} t \mathrm{~d} t
$$

and

$$
\frac{\left(\sigma_{\theta}-\sigma_{r}\right) h^{2}}{2 P(\mathrm{I}-\nu)}=\frac{\mathrm{I}}{2 \pi} \int_{0}^{\infty} F_{-\nu}\left[\frac{\mathcal{f}_{\mathrm{I}}(t R)}{t R / 2}-\mathcal{F}_{\mathrm{o}}(t R)\right] \frac{\mathcal{f}_{\mathrm{I}}(t B)}{t B / 2} t \mathrm{~d} t,
$$

where

$$
F_{ \pm \nu}=\frac{\left(\mathrm{I} 2 t^{2}-2 H^{4}\right) \sinh t+H^{4}(\sinh t+t \cosh t) /(\mathrm{I} \pm v)}{\mathrm{I} 2 t\left(\sinh ^{2} t-t^{2}\right)+H^{4}(\sinh 2 t+2 t)} .
$$

In these equations $\sigma_{r}$ is the radial stress, $\sigma_{\theta}$ is the tangential stress, $P$ is the total load, $\nu$ is Poisson's ratio for ice, $h$ is the ice thickness, $B$ is $b / h, b$ is the radius of the load distribution, $R$ is $r / h, r$ is the radial coordinate, $H$ is $h / l, l^{4}$ is $E h^{3} /\left[12 k\left(1-\nu^{2}\right)\right], E$ is Young's modulus for ice, $k$ is the unit weight of water, and $t$ is the Hankel transform parameter for $R$.

Typical values of $H$ are between 0.0 I and 0.1 for ice sheets floating on water. Hence it can be shown that the $\mathrm{H}^{4}$ terms in the numerator of $F_{ \pm \nu}$ (Equation (4)) produce negligible results when compared to results from the $12 t^{2} \sinh t$ term. Hence, in place of $F_{ \pm \nu}$ we may use $F$ where

$$
F=\frac{\mathrm{I} 2 t^{2} \sinh t}{\mathrm{I} 2 t\left(\sinh ^{2} t-t^{2}\right)+H^{4}(\sinh 2 t+2 t)} .
$$

If thin-plate theory is used to represent the ice sheet, the formulas for the stresses are the same as Equations (2) and (3) except that now the $F$ function becomes

$$
F_{\mathrm{p}}=\frac{3^{t^{2}}}{t^{4}+H^{4}} \text {. }
$$

Consider the stresses directly under a concentrated load, $R=B=0$. For the stress sum $\sigma_{\theta}+\sigma_{r}$, the integrand becomes $F$ times $t$. For plate theory, $F_{\mathrm{p}}$ times $t$ is approximately $3 / t$ for very large $t$. Hence, the $\sigma_{\theta}+\sigma_{r}$ integral diverges for plate theory when $R=B=0$. For elastic layer theory, $F$ from Equation (5) is $3^{t^{2}} /\left(t^{4}+H^{4}\right)$ when $t$ is small, which is the

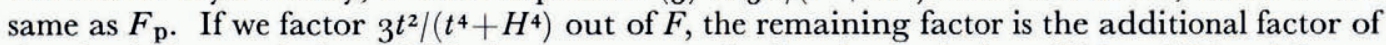
the elastic-layer solution which does not appear in the plate solution. This additional factor is shown in Figure $\mathrm{I}$, and, for $H<0 . \mathrm{I}$, it is nearly independent of $H$. This additional factor becomes $2 t^{3} \exp (-t) / 3$ for large $t$, which provides convergence for the $\sigma_{\theta}+\sigma_{r}$ integral when $t$ goes to infinity.

In order to perform the integration for $\sigma_{\theta}+\sigma_{r}$ in Equation (2) when $R=B=0$, the integration is divided into regions. In the region from $t=0$ to $t=2$, the convergence factor is expanded into a series about $t=0$ and the integration performed. In the region from $t=2$ to $t=\infty$, the integration can be performed after the integrand has been expanded into an asymptotic series. The result is

$$
\frac{\left(\sigma_{\theta}+\sigma_{r}\right)^{0} h^{2}}{{ }_{2} P(\mathrm{I}+\nu)}=0.8300-\frac{3}{2 \pi} \log H-\frac{H^{2}}{40},
$$

where the zero superscript designates $R=B=0$.

Let us now subtract $\left(\sigma_{\theta}+\sigma_{r}\right)^{0}$ from $\sigma_{\theta}+\sigma_{r}$. Using a superscript star to designate this difference, we have

$$
\frac{\left(\sigma_{\theta}+\sigma_{r}\right)^{\star} h^{2}}{2 P(\mathrm{I}+\nu)}=\frac{\mathrm{I}}{2 \pi} \int_{0}^{\infty} F\left[\mathcal{f}_{0}(t R) \frac{\mathcal{f}_{\mathrm{I}}(t B)}{t B / 2}-\mathrm{I}\right] t \mathrm{~d} t .
$$




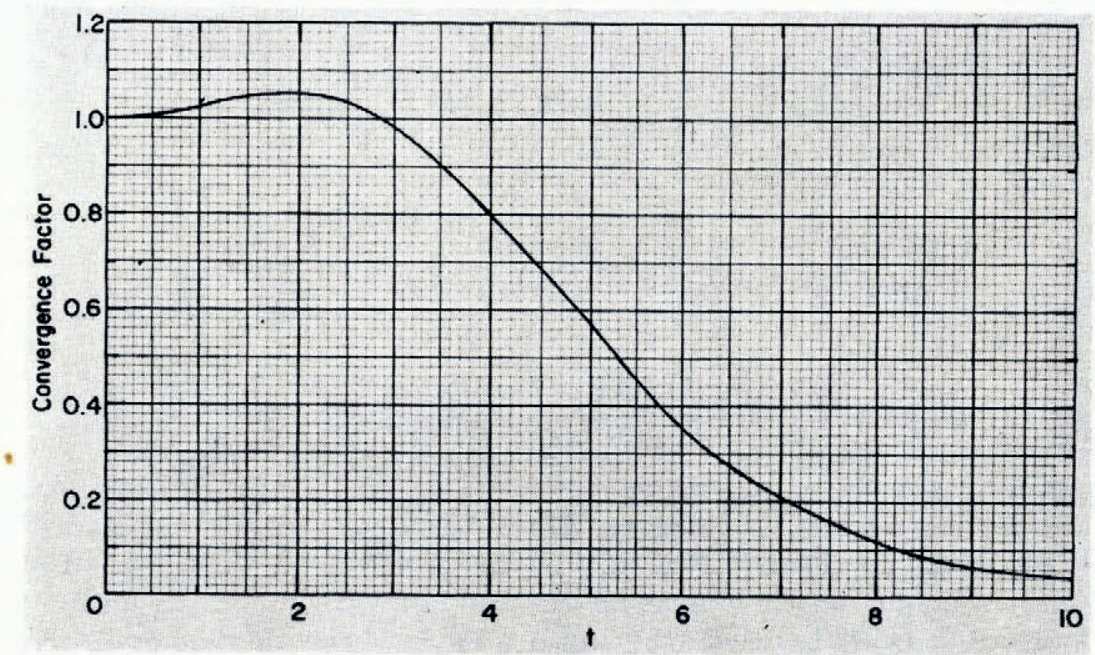

Fig. I. Convergence factor.

The factor $F$ in the integrand depends on $H$ only near $t=0$, while the factor $\mathcal{J}_{0}(t R) \mathcal{F}_{\mathrm{I}}(t B) /$ $(t B / 2)-\mathrm{I}$ is very small near $t=0$. Hence, one might suspect that the integral of the product may be nearly independent of $H$. When $H=0, F$ becomes

$$
F_{0}=\frac{t / 2}{\sinh t+t}+\frac{t / 2}{\sinh t-t} .
$$

In order to estimate the error in using $F_{0}$ in Equation (8) rather than $F$, consider

$$
\frac{\left(\sigma_{\theta}+\sigma_{r}\right) \mathrm{e}^{\star} h^{2}}{2 P(\mathrm{I}+\nu)}=\frac{\mathrm{I}}{2 \pi} \int_{0}^{\infty}\left(F-F_{0}\right)\left[\mathcal{f}_{0}(t R) \frac{\mathcal{f}_{\mathrm{I}}(t B)}{t B / 2}-\mathrm{I}\right] t \mathrm{~d} t,
$$

where the subscript e represents the error of neglecting $H$. Since $F-F_{0}$ is zero except near $t=0$, we can expand the Bessel function into a series about $t=0$. Retaining only the first significant term we integrate to obtain

$$
\frac{\left(\sigma_{\theta}+\sigma_{r}\right) \mathrm{e}^{\star} h^{2}}{2 P(\mathrm{I}+v)}=\frac{3 H^{2}}{64}\left(B^{2}+2 R^{2}\right) .
$$

Let us now consider the stress difference $\sigma_{\theta}-\sigma_{r}$ of Equation (3). The factor $\mathcal{J}_{\mathrm{I}}(t R) /$ $(t R / 2)-\mathcal{F}_{0}(t R)$ of the integrand is small near $t=0$, and hence, one might suspect again that the integral is nearly independent of $H$. We can estimate the error of neglecting $H$ by considering $F-F_{0}$. Proceeding as before we get

$$
\frac{\left(\sigma_{\theta}-\sigma_{r}\right)_{\mathrm{e}} h^{2}}{2 P(\mathrm{I}-\nu)}=\frac{-3 H^{2} R^{2}}{64} .
$$

Equations (I I) and (12) were compared with results obtained from numerical integration and the error was less than $0.000 \mathrm{I}$ when $H=0 . \mathrm{I}, B=2$, and $R=3$. The error is even less when $H, B$, or $R$ is less than the stated values.

Hence we can now consider the stresses of Equations (3) and (8) using $F_{\mathrm{o}}$ rather than $F$, which makes the integrals independent of $H$. The integrals were numerically integrated in steps of o.o I from $t=0$ to $t=10$ by means of Simpson's quadrature. Results were obtained when the radial coordinate $R$ was varied in steps of 0.1 from o to 3 while the radius of the 


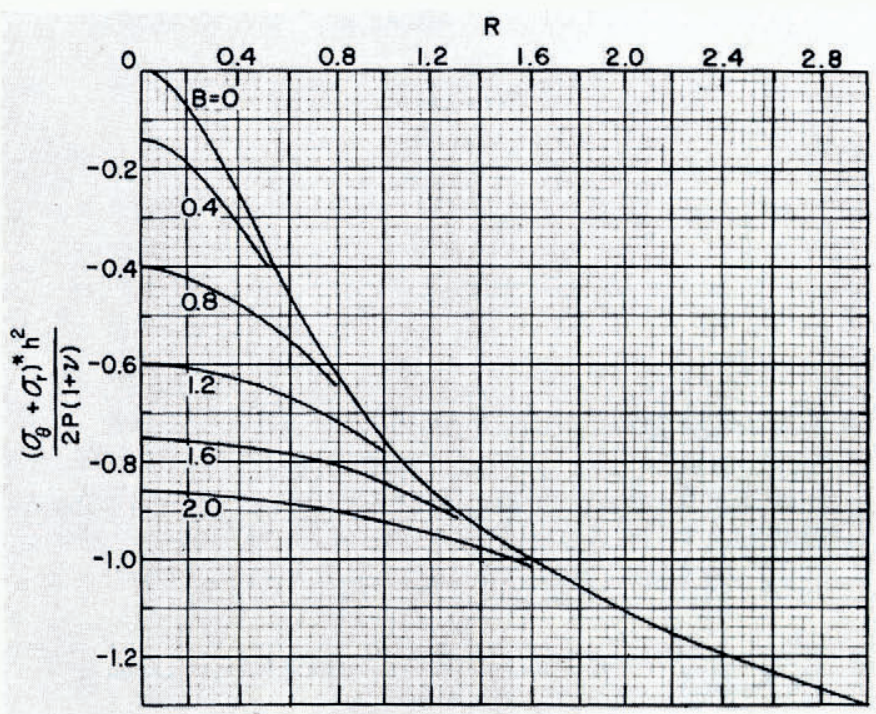

Fig. 2. Stress sum as a function of $B$ and $R$.

load distribution was varied in steps of $0 . \mathrm{I}$ from o to 2. The results for $\left(\sigma_{\theta}+\sigma_{r}\right)^{\star}$ are shown in Figure 2. To this result must be added Equations (7) and (I I) to obtain the total $\sigma_{\theta}+\sigma_{r}$. The results for $\sigma_{\theta}-\sigma_{r}$ are shown in Figure 3. To this result must be added the solution of Equation (12) to obtain the total $\sigma_{\theta}-\sigma_{r}$.

At a sufficiently large $R$, the elastic-layer theory and the thin-plate theory should predict the same results. One would expect the greatest difference between these theories when $B=0$. Table I shows the difference between these two solutions as functions of $R$.

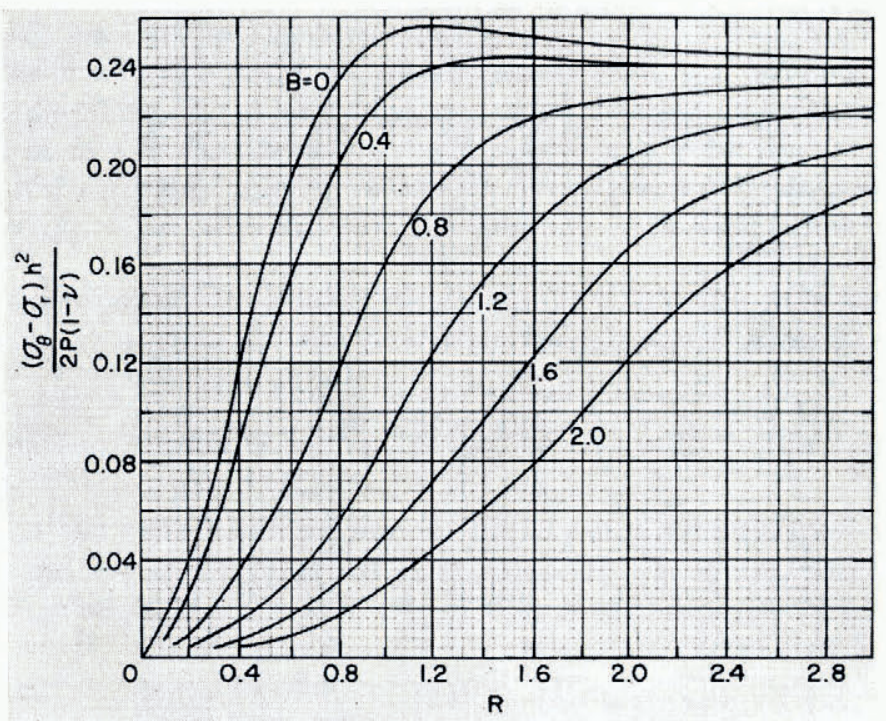

Fig. 3. Stress difference as a function of $B$ and $R$. 
TABle I. Elastic-layer theory minus plate theory

$\begin{array}{lrr}R & \frac{\left(\sigma_{\theta}+\sigma_{r}\right)^{\star}}{2 P(\mathrm{I}+\nu)} & \frac{\left(\sigma_{\theta}-\sigma_{r}\right) h^{2}}{2 P(\mathrm{I}-\nu)} \\ 0.5 & 0.0744 & -0.0757 \\ 1.0 & 0.0148 & 0.0140 \\ 1.5 & 0.0019 & 0.0139 \\ 2.0 & 0.0013 & 0.008 \mathrm{I} \\ 2.5 & 0.0013 & 0.0052 \\ 3.0 & 0.0013 & 0.0036\end{array}$

\section{Regtangular LOADS}

The solution for a load uniformly distributed over a rectangular area is obtained in a similar manner as for a circular load. The difference being that now Fourier transforms with respect to $x$ and $y$ are utilized rather than a Hankel transform with respect to $r$. Since the general method of solution has been previously given by Woinowsky-Krieger (1933), it will not be repeated here. The stresses at the bottom of the ice sheet are

$$
\begin{aligned}
& \frac{\left(\sigma_{x}+\sigma_{y}\right) h^{2}}{2 P(\mathrm{I}+\nu)}=\frac{\mathrm{I}}{\pi^{2}} \int_{0}^{\infty} \int_{0}^{\infty} F_{+\nu} \frac{\sin \alpha A}{\alpha A} \frac{\sin \beta B}{\beta B} \cos \alpha X \cos \beta \gamma \mathrm{d} \alpha \mathrm{d} \beta, \\
& \frac{\left(\sigma_{x}-\sigma_{y}\right) h^{2}}{{ }_{2} P(\mathrm{I}-\nu)}=\frac{\mathrm{I}}{\pi^{2}} \int_{0}^{\infty} \int_{0}^{\infty} F_{-\nu} \frac{\alpha^{2}-\beta^{2}}{t^{2}} \frac{\sin \alpha A}{\alpha A} \frac{\sin \beta B}{\beta B} \cos \alpha X \cos \beta \gamma \mathrm{d} \alpha \mathrm{d} \beta,
\end{aligned}
$$

and

$$
\frac{\sigma_{x y} h^{2}}{P(\mathbf{I}-\nu)}=\frac{\mathrm{I}}{\pi^{2}} \int_{0}^{\infty} \int_{0}^{\infty} F_{-\nu} \frac{2 \alpha \beta}{t^{2}} \frac{\sin \alpha B}{\alpha A} \frac{\sin \beta B}{\beta B} \sin \alpha X \sin \beta Y \mathrm{~d} \alpha \mathrm{d} \beta .
$$

where all notations are the same as for the circular load except that now $\sigma_{x}$ is the stress in the $x$ direction, $\sigma_{y}$ is the stress in the $y$ direction, $\sigma_{x y}$ is the shear stress in the $x-y$ plane, $X$ is $x / h$, $x$ is the $x$ coordinate, $Y$ is $y / h, y$ is the $y$ coordinate, $A$ is $a / h, a$ is the half-length of the load distribution in the $x$ direction, $B$ is $b / h, b$ is the half-length of the load distribution in the $y$ direction, $\alpha$ is the Fourier transform parameter for $X, \beta$ is the Fourier transform parameter for $Y$, and $t^{2}$ is $\alpha^{2}+\beta^{2}$. The solution for a rectangular load using thin-plate theory is given by Equations (I3), (I4) and (I5) provided $F_{ \pm \nu}$ is replaced with $F_{\mathrm{p}}$. As in the circular load case, we may neglect the $H^{4}$ terms in the numerator of $F_{ \pm v}$, and replace $F_{ \pm v}$ with $F$. For a concentrated load at $x=y=0, \sigma_{x}-\sigma_{y}$ and $\sigma_{x y}$ are zero while $\sigma_{x}+\sigma_{y}$ gives the same result as $\sigma_{\theta}+\sigma_{r}$.

In order to reduce the effect of $H$ on $\sigma_{x}+\sigma_{y}$, let us subtract the concentrated load solution at $x=y=0$. Designating this difference with a superscript star, we have

$$
\frac{\left(\sigma_{x}+\sigma_{y}\right)^{\star} h^{2}}{2 P(\mathrm{I}+\nu)}=\frac{\mathrm{I}}{\pi^{2}} \int_{0}^{\infty} \int_{0}^{\infty} F\left[\frac{\sin \alpha A}{\alpha A} \frac{\sin \beta B}{\beta B} \cos \alpha X \cos \alpha Y-\mathrm{I}\right] \mathrm{d} \alpha \mathrm{d} \beta .
$$

As in the circular-load case, we suspect that the integrals of Equations (14), (15), and (I6) are relatively independent of $H$. An estimate of the error for neglecting $H$ in $F$ for these integrals can be made by replacing $F$ with $F-F_{0}$. Expanding the sines and cosines into a series and proceeding as before we obtain

$$
\frac{\left(\sigma_{x}+\sigma_{y}\right) \mathrm{e}^{\star} h^{2}}{2 P(\mathrm{I}+\nu)}=\frac{3 H^{2}}{\mathrm{I} 6}\left[\frac{A^{2}+B^{2}}{6}+\frac{X^{2}+Y^{2}}{2}\right],
$$




$$
\begin{aligned}
& \text { CONGENTRATED LOADS ON IGE } \\
& \frac{\left(\sigma_{x}-\sigma_{y}\right)_{\mathrm{e}} h^{2}}{P(\mathrm{I}-\nu)}=\frac{3 H^{2}}{3^{2}}\left[\frac{A^{2}-B^{2}}{6}+\frac{X^{2}-Y^{2}}{2}\right], \\
& \frac{\left(\sigma_{x y}\right)_{\mathrm{e}} h^{2}}{P(\mathrm{I}-\nu)}=\frac{-3 H^{2}}{3^{2}} X Y .
\end{aligned}
$$

Hence, we can now consider the stresses of Equations (I4), (I5), and (I6) using $F_{0}$ rather than $F$, which makes the integrals independent of $H$. However, the solutions are still a function of the load distribution $A$ and $B$ as well as the coordinates $X$ and $Y$. In order to reduce the number of parameters to a manageable level, let us consider the stresses directly under the center of the load at $X=Y=0$. For this case $\sigma_{x y}=0$. The other two integrals were

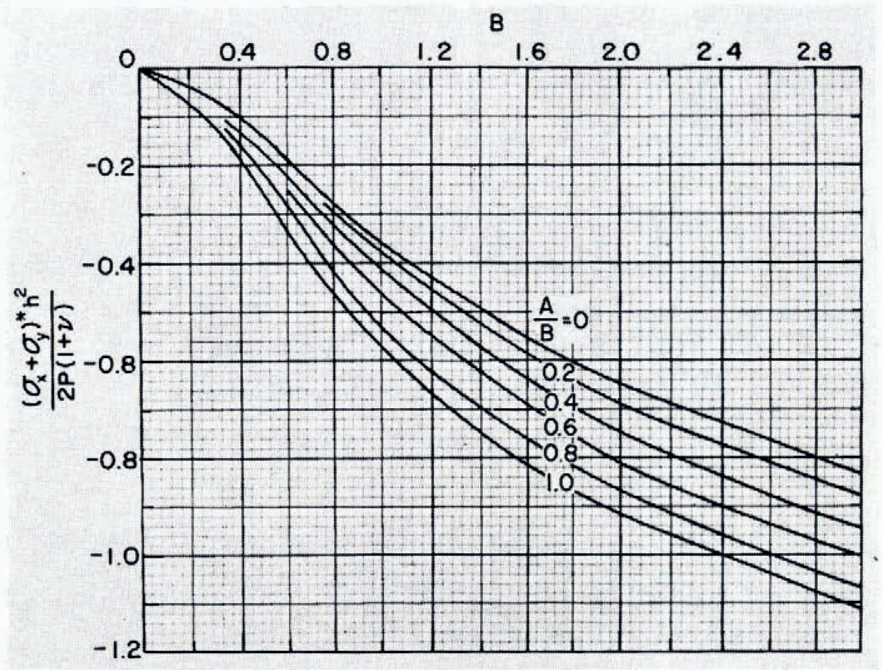

Fig. 4. Stress sum at $X=Y=o$ as a function of $B$ and $A / B$.

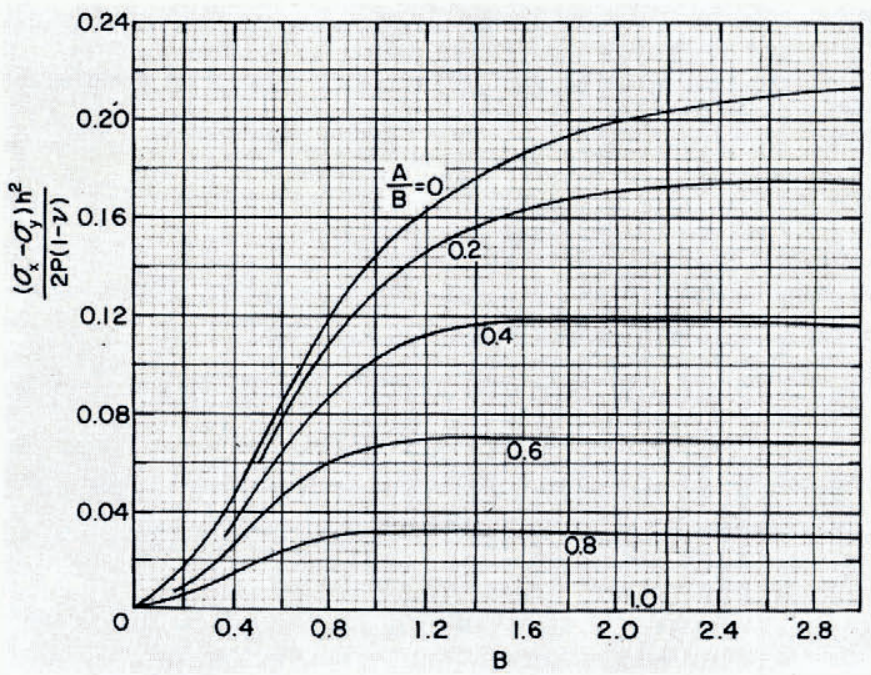

Fig. 5. Stress difference at $X=Y=O$ as a function of $B$ and $A / B$. 
numerically integrated in steps of o. I from $\alpha=0$ to $\alpha=$ Io and in steps of 0 . I from $\beta=0$ to $\beta=$ Io by means of Simpson's quadrature in two variables. The load distribution distance $B$ was varied in steps of o.I from o to 3 while the ratio $A / B$ was varied in steps of 0.2 from o to $\mathrm{I}$. The result for $\left(\sigma_{x}+\sigma_{y}\right)^{\star}$ is shown in Figure 4. Interchanging $A$ and $B$ does not change the value of $\left(\sigma_{x}+\sigma_{y}\right)^{\star}$. The result for $\sigma_{x}-\sigma_{y}$ is shown in Figure 5. Interchanging $A$ and $B$ changes the sign of $\sigma_{x}-\sigma_{y}$.

\section{CONCLUSIONS AND RECOMMENDATIONS}

The stresses in the vicinity of a relatively concentrated load have been determined for loads distributed over both circular and rectangular areas by using elastic-layer theory. This corrects the deficiency of overestimating these stresses created by thin-plate theory.

Although the problem has been solved, it still would be desirable to develop a more convenient algorithm of computation than straight numerical integration. One approach would be to use approximation functions. For example, the approximation

$$
\frac{\left(\sigma_{\theta}+\sigma_{r}\right)^{\star} h^{2}}{2 P(\mathrm{I}+\nu)}=\left(\mathrm{I}+B^{2}\right)^{-\mathrm{I}}\left(\mathrm{I}+R^{2}\right)^{B-2}-\mathrm{I},
$$

seems to work reasonably well if $B$ and $R$ are not too large.

Another more rational approach would be to develop the integrand into a series and integrate. However a power series development does not work. More hopeful is to develop the integrand into a Bessel-function series and integrate each term by means of contour integration. This method, although rather complicated may produce a better computation algorithm.

\section{REFERENGES}

Hertz, H. [R.] 1884. Über das Gleichgewicht schwimmender elastischer Platten. Annalen der Physik und Chemie, Neue Folge [Wiedemann], Bd. 22, Ht. 7, p. 449-55.

Nadai, A. 1920. Die Biegungsbeanspruchung von Platten durch Einzelkräfte. Schweizerishe Bauzeitung, Jahrg. 76 , Ht. 23, p. 257-6o.

Nadai, A. 1925. Die elastischen Platten. Berlin, Julius Springer.

Nevel, D. 1970. Concentrated loads on plates. U.S. Cold Regions Research and Engineering Laboratory. Research Report 265 .

Westergaard, H. 1926. Stresses in concrete pavements computed by theoretical analysis. Public Roads, Vol. 7, No. 2, p. 25-35.

Woinowsky-Krieger, S. 1933. Der Spannungszustand in dicken elastischen Platten. Ingenieur-Archiv, Bd. 4, Ht. 3, p. 203-26; Ht. 4, p. 305-31.

\section{DISGUSSION}

L. Lliboutry: All your calculations assume perfect elasticity. Have you done any calculations taking creep (especially transient creep) into account?

D. E. Nevel: Yes. This work has been described in another recent report of mine (Nevel, 1976).

E. Vittoratos: One practical problem with Bessel-function expansions would be that these functions are not available in pre-programmed form in calculators or micro-processors; one generally needs a rather large computer.

Nevel: Usually in bearing-capacity problems the arguments of the Bessel functions are not too large. Hence a series expansion is an efficient method of computation. In the case of the modified Bessel functions (ber, bei, ker, kei), the computational method of using a recurrence 
relation between the different functions and their derivatives (Nevel, I959) is efficient in terms of computer space and time. The "safe" bearing capacity program of CRREL utilizes this method in a subroutine. The computation is done on a desk-top calculator, the HewlettPackard 9820. There are some new hand-held calculators, such as the HP-67, in which I believe this computer program can be made to work. The real computational problem appears to be with the Fourier-series solutions which occur when rectangular coordinates are used. The series are slowly convergent when the arguments are small. The method of expanding the sines and cosines into a Bessel series and integrating by contour methods may provide a more convergent series which would solve this problem.

\section{REFERENCES}

Nevel, D. 1959. Tables of Kelvin functions and their derivatives. U.S. Snow, Ice and Permafrost Research Establishment. Technical Report 67.

Nevel, D. 1976 . Creep theory for a floating ice sheet. U.S. Cold Regions Research and Engineering Laboratory. Special Report 76-4. 